\title{
A Design of Sustainable System towards Green Architecture
}

\author{
Xu Tan and Songwen Tan
}

\begin{abstract}
Regarding the world-wide environmental issues, the modern architecture has entered a place of technology forming a sustainable architecture. Sustainable systems designed for the buildings have been largely carried out to reduce waste emissions. As most effort is spent on utilizing the natural resources, the resources from building itself have been neglected. In this work, we present a design of sustainable system focusing on the resources from building itself. Spatial arrangement as a key design factor for sustainable buildings is considered in the building design. Using the knowledge of civil and environmental engineering, kitchen waste is mixed with toilet sewage in a special sewerage system connected with a wastewater treatment system. The biogas produced by the wastewater treatment system is designed to be collected and used for power generation. This work may suggest an idea to reduce waste emissions and energy consumption for sustainable buildings towards an advanced green architecture.
\end{abstract}

Index Terms-Design, spatial arrangement, sustainable architecture, wastewater treatment.

\section{INTRODUCTION}

In recent decades, environmental pollution as a world-wide problem has been spent much attention. As environmental impact is a key factor in building assessment nowadays, modern architecture has entered a stage of science and engineering turning to sustainable architecture, called green architecture, applying energy and ecological technologies in designs of buildings [1], [2]. Typically, hazardous gas pollution in cities requires a good design of modern building to minimize health threat using air fluid mechanism [3]. Wastewater generated by residences requires a treatment considered in the design of the building. Kitchen waste can be separated from the household garbage and used to produce energy. Also for health and education purposes, environmental protection and energy saving are important to us that need to be addressed in our daily life, design of a sustainable system for green buildings has been an emerging topic now [4], [5].

Generally, there is a large consumption of energy, electricity, water and materials in buildings, where a lot of people live in. Sustainable systems designed for the buildings have been largely carried out to reduce waste emissions [6]. Typically, the design of the BRB embraces the moderate

Manuscript received July 23, 2016; revised October 12, 2016.

$\mathrm{Xu}$ Tan is with the Faculty of Design, Architecture and Building, University of Technology Sydney (UTS), Sydney, NSW 2007 Australia (e-mail: nancy_tx@126.com).

Songwen Tan is with the Faculty of Engineering and Information Technologies, University of Sydney, Sydney, NSW 2006 Australia (e-mail: stan0309@uni.sydney.edu.au). climate of Ireland uses the natural wind as energy resource. The Exploratorium at Pier 15 in San Francisco, as near the ocean, utilizes water from the ocean in its cooling-heating system. The J. Craig Venter Institute in California uses the LEED-Platinum system for photovoltaic application. As most effort is spent on utilizing the natural resources, the resources from building itself have been neglected.

In this work, we present a design of sustainable system focusing on the resources from building itself. Using the knowledge of civil and environmental engineering, kitchen waste is mixed with toilet sewage in a special sewerage system connected with a wastewater treatment system. The biogas produced by the wastewater treatment system is designed to be collected and used for power generation. This work may suggest an idea to reduce waste emissions and energy consumption for sustainable buildings towards an advanced green architecture.

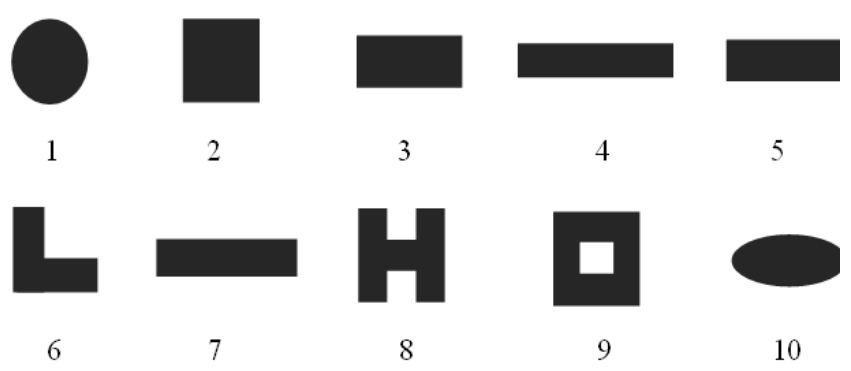

Fig. 1. Shapes of buildings listed in the increasing order of the shape coefficient.

\section{DESIGN OF THE BUILDING SHAPE}

First of all, a key design factor for sustainable buildings is the spatial arrangement. Sustainable buildings must have a designed structure with efficient energy consumption, including the energy, air and water supply. Thus for well-designed sustainable buildings, apart from the function of facility, the structure factor, such as shape, stairways, level height, windows, doors and building structure. For instance, ventilation systems are required to consider the air mechanics in order to give the best design for air transfer in sustainable buildings. Shape coefficient as an important factor related with energy consumption, showing the surface area which the building contacts with the environment. A building with smaller shape coefficient commonly can be account for lower energy consumption of electricity, water transport and air ventilation. Fig. 1 shows the relationship between the shape and the shape coefficient $(\mathrm{f}(\mathrm{s}))$, in the increasing order of the $\mathrm{f}(\mathrm{s})$ : round structure $(\mathrm{f}(\mathrm{s})$ is 0.16$)<$ square structure $(\mathrm{f}(\mathrm{s})$ is $0.17)<$ rectangular structure at length to width ratio of $2(\mathrm{f}(\mathrm{s})$ is 0.18$)<$ rectangular structure at length to width ratio of 5 ( $\mathrm{f}(\mathrm{s})$ 
is 0.18$)$ rectangular structure at length to width ratio of 3 ( $\mathrm{f}(\mathrm{s})$ is 0.19$)<\mathrm{L}$-shape structure $(\mathrm{f}(\mathrm{s})$ is 0.19$)<$ rectangular structure at length to width ratio of $4(\mathrm{f}(\mathrm{s})$ is 0.20$)<\mathrm{I}$-shape structure $(\mathrm{f}(\mathrm{s})$ is 0.21$)<$ rectangular ambulatory plane structure $(\mathrm{f}(\mathrm{s})$ is 0.26$)<$ oval structure $(\mathrm{f}(\mathrm{s})$ is 0.29$)$.

However, the practical applications do not always obey this shape coefficient for prediction of energy consumption, while many other factors are required to be considered, like human activity, elevators, toilets, pipes and electrical devices. For example, a building with round structure has the smallest shape coefficient, while a building with I-shape structure has the lowest value of total energy consumption and is much more convenient for people to move in the building.

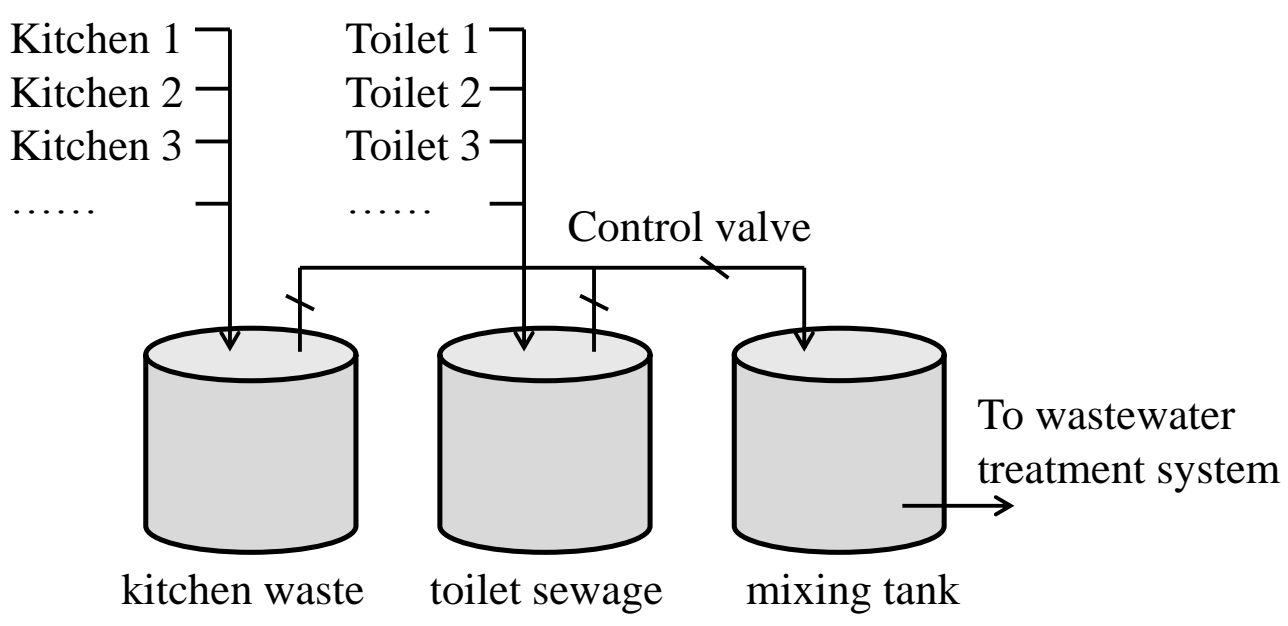

Fig. 2. Design of the sewerage system for sustainable purpose.

\section{Design of The Sustainable System}

As the most efficient energy supplier, advanced sunlight equipment such as photovoltaic sunlight system helps to support renewable electrical energy for daily energy consumption. Electricity outputs of a photovoltaic sunlight system largely rely on height, angles, latitude and longitude, weather and climate conditions. Solar system gains different energy even at the same places. Especially, efficiency of common used photovoltaic sunlight system ranges at 4 28\%. A bad efficiency of sunlight system would largely influence its pay-return time of its cost. However, bad efficiencies do not present photovoltaic sunlight systems cannot significantly reduce energy consumption. Actually many people have used photovoltaic sunlight systems in their houses and buildings. Top roof is usually adjusted to a good angle for sunlight adsorption to achieve high energy production using photovoltaic sunlight systems. At northern places, an angle facing the south can increase the energy production for this photovoltaic energy generation system. Whereas much northerner places during the winter, such as Norway, solar resource cannot be utilized. In order to increase the energy production during the winter, a photovoltaic panel must be angled at positive 15 degree of horizontal latitude, while during the summer negative 15 degree should be set. And during other time of a year, difference between the angle of photovoltaic panel and horizontal latitude should be set at 0 degree as usual. Solar systems have also been used to heat water for daily use. Universally, the solar heating system as an efficient method to collect sunlight energy, which is free, with low cost has been used in almost modern residence places. Besides, a well-deigned wind system to produce wind energy has been used in some green buildings. However by considering the ratio of cost to efficiency, small-scaled wind energy system is not suitable for most green buildings since the wind-energy system is expensive while the efficiency of electricity generation is relatively low.

A sustainable building is designed to reduce energy consumption. In this work, we present a design of sustainable system focusing on the resources from building itself. Using the knowledge of civil and environmental engineering, kitchen waste is mixed with toilet sewage in a special sewerage system connected with a wastewater treatment system. As shown in Fig. 2, all kitchen waste from different rooms in the building is collected together and stored in a kitchen waste tank, while all toilet wastewater is collected and stored in a toilet sewage tank. As the process of wastewater treatment largely rely on controlling the fraction of organic contents in the wastewater. Control valves are used to adjust the ratio of solid to liquid in mixing tank. After a short time of storage in the sewerage system, mixed wastewater containing a large amount of biomass is designed to pump into a wastewater treatment system for reducing emissions and generating biogas power.

\section{WAStewater TREATMENT AND Biogas POWER GENERATION}

The biomass wastewater collected from kitchens and toilets in the building is treated by the wastewater treatment system (Fig. 3), containing the biological contact anaerobic reactor (BCAR), the membrane bioreactor (MBR), the biogas power generator and some assistance devices. After pumping the wastewater into the BCAR tank, anaerobic biodegradation of organic substances is implemented. The BCAR system has three groups of fibre carriers for loading activated sludge. 
During the anaerobic reaction, organic substances are degraded to smaller molecules and produce some kinds of biogas, like methane. These biogases then are transport to the powder generation system. The anaerobic treated wastewater is pumped into a storage tank for $\mathrm{pH}$ adjustment and biological stabilization. After that, a membrane bioreactor is used for aerobic biodegradation which can break down most biomass to substances with low environmental contamination. In the MBR system, the membrane made of polypropylene with a filtration area of $1 \mathrm{~m} 2$ (pore size of $0.2 \mu \mathrm{m}$ ) is designed. The size of membrane is $60 \mathrm{~cm} \times 50 \mathrm{~cm} \times 10 \mathrm{~cm}$. All tanks and reactors drew in the Figure 3 are $70 \mathrm{~cm} \times 60 \mathrm{~cm} \times 30 \mathrm{~cm}$, having an effective volume of $126 \mathrm{~L}$. Porous aerators are set at the bottom of the MBR tank to maintain the oxygen concentration at $2.5 \mathrm{mg} / \mathrm{L}$. Temperature is set at $20{ }^{\circ} \mathrm{C}$ with a temperature controller. After the MBR biodegradation, the wastewater can be directly discharged to the environment or the city drains network. The solid waste separated by MBR on the filter is mixed with common solid waste after dehydration. At last, the power generator uses the biogas to generate electric energy which can be used to support the public electricity consumption in the building.

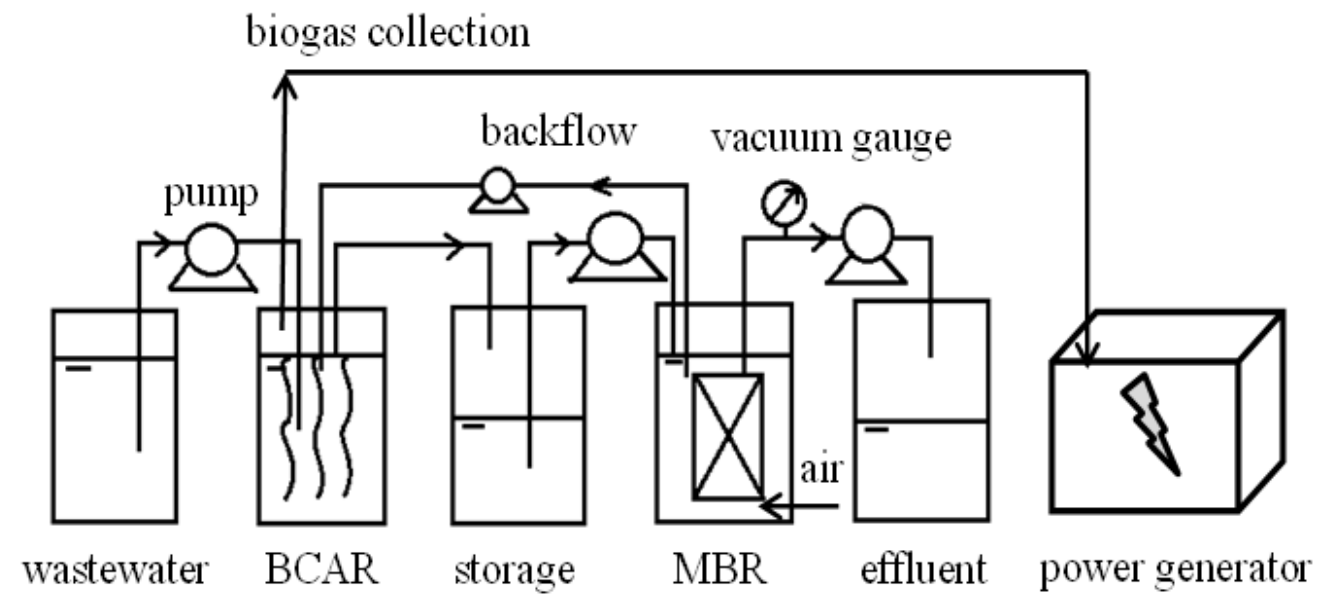

Fig. 3. Design of the wastewater treatment system for sustainable purpose.

\section{CONCLUSIONS}

While highly regarding the world-wide environmental issues, the modern architecture has entered a place of technology forming a sustainable architecture. Sustainable systems designed for the buildings have been largely carried out to reduce waste emissions. As most effort is spent on utilizing the natural resources, the resources from building itself have been neglected. In this work, we present a design of sustainable system focusing on the resources from building itself. Using the knowledge of civil and environmental engineering, kitchen waste is mixed with toilet sewage in a special sewerage system connected with a wastewater treatment system. The biogas produced by the wastewater treatment system is designed to be collected and used for power generation. This work may suggest an idea to reduce waste emissions and energy consumption for sustainable buildings towards an advanced green architecture.

Spatial arrangement as a key design factor for sustainable buildings should consider the structure factor, such as shape, stairways, level height, windows, doors and building structure. Shape coefficient as an important factor related with energy consumption. The shape coefficients are listed in the increasing order: round structure < square structure < rectangular structure at length to width ratio of $2<$ rectangular structure at length to width ratio of $<$ rectangular structure at length to width ratio of $3<\mathrm{L}$-shape structure < rectangular structure at length to width ratio of $4<$ I-shape structure < rectangular ambulatory plane structure < oval structure. However, the practical applications do not always obey this shape coefficient for prediction of energy consumption, while many other factors are required to be considered.
Besides, we also present a design of sustainable system focusing on the resources from building itself. Using the knowledge of civil and environmental engineering, kitchen waste is mixed with toilet sewage in a special sewerage system connected with a wastewater treatment system. The biomass wastewater collected from kitchens and toilets in the building is treated by the wastewater treatment system, containing the biological contact anaerobic reactor, the membrane bioreactor, the biogas power generator and some assistance devices. After the wastewater treatment, the wastewater can be directly discharged to the environment or the city drains network. The solid waste separated by the wastewater treatment system is mixed with common solid waste after dehydration. The power generator uses the biogas to generate electric energy which can be used to support the public electricity consumption in the building.

\section{ACKNOWLEDGMENT}

Our gratitude goes to the staff in the Faculty of Design, Architecture and Building, University of Technology Sydney (UTS) and the staff in the Faculty of Engineering and Information Technologies, University of Sydney for their kind assistance.

\section{REFERENCES}

[1] S. Guy and G. Farmer, "Reinterpreting sustainable architecture: The place of technology," Journal of Architectural Education, vol. 54, pp 140-148, Feb 2001.

[2] M. T. Borzacchiello, V. Torrieri, and P. Nijkamp, "An operational information systems architecture for assessing sustainable transportation planning: principles and design," Eval Program Plann, vol. 32, pp. 381-9, Nov. 2009

[3] X. P. Liu, J. L. Niu, K. C. Kwok, J. H. Wang, and B. Z. Li, "Local characteristics of cross-unit contamination around high-rise building 
due to wind effect: mean concentration and infection risk assessment," J Hazard Mater, vol. 192, pp. 160-7, Aug. 15, 2011.

[4] R. Guenther, "Sustainable architecture for health: a mindset shift," HERD, vol. 2, pp. 3-9, Summer 2009.

[5] K. T. Cuddeback, "Sustainable healthcare architecture 2nd edition," HERD, vol. 7, pp. 151-4, Winter 2014

[6] J. H. Clarke, "The design and location of building inlets and outlets to minimize wind effect and building re-entry of exhaust fumes," Am Ind Hyg Assoc J, vol. 26, pp. 242-8, May-Jun .1965.

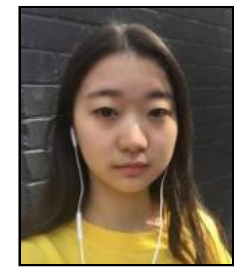

Xu Tan was born on in 1997, in China. She is now studying in sustainable architecture as an undergraduate student at the Faculty of Design, Architecture and Building, University of Technology Sydney (UTS), Sydney, NSW, Australia.

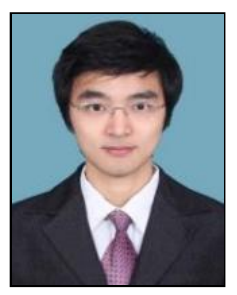

Songwen Tan was born in 1990, in China. He earned the bachelor degree in Harbin Institute of Technology, China in 2012, majoring in environmental engineering and the master degree in Korea University, South Korea in 2015 with the major of bio-microsystem engineering. He is now with the Faculty of Engineering and Information Technologies, University of Sydney, Sydney, NSW, Australia.

He worked in China as an engineer for 2 years. Now he is working as a tutor in the Faculty of Engineering and Information Technologies, University of Sydney, Sydney, NSW, Australia. He has published several papers in the fields of environmental engineering, chemical and biological engineering. 